ROBERTO MANNU $(* *)\left({ }^{\circ}\right)$ - GIANNI GILIOLI $(* * *)$ - PIETRO LUCIANO $(*)$

\title{
OCCUPANCY OF THE TERRITORY BY LYMANTRIA DISPAR (L.) (LEPIDOPTERA EREBIDAE) EGG MASSES AS A PREDICTIVE INDEX OF DAMAGE
}

\author{
(*) Sezione di Patologia Vegetale ed Entomologia, Università degli Studi di Sassari, Viale Italia 39, 07100 Sassari, Italy \\ (**) Istituto per lo Studio degli Ecosistemi, Consiglio Nazionale delle Ricerche, Traversa la Crucca 3, 07100 Sassari, Italy \\ (***) Dipartimento di Medicina Molecolare e Traslazionale, Università di Brescia, Viale Europa 11, 25123 Brescia, Italy \\ $\left.{ }^{\circ}\right)$ Corresponding author: Roberto Mannu, e-mail: roberto.mannu@ise.cnr.it
}

Mannu R., Gilioli G., Luciano P. - Occupancy of the territory by Lymantria dispar (L.) (Lepidoptera Erebidae) egg masses as a predictive index of damage.

In Sardinia (Italy) the population abundance of the defoliator gypsy moth Lymantria dispar (L.) (Lepidoptera Erebidae) has been regularly sampled for over thirty years by counts of egg masses. This monitoring activity allows annual identification of the areas with the highest abundance of infestation in order to define the areas to be subjected to phytosanitary treatments and thus to confine the damage caused by gypsy moth defoliation. However, the identification of areas to be treated have been defined exclusively according to the experience gained over the years by the operators. To overcome the limitation of this empirical approach we have developed an objective method supporting decision making based on the relationship between the percentage of infested sites and the intensity of defoliation. For this purpose the radius of annual gypsy moth expansion was estimated in a cork oak district: the estimated value was ca. $6 \mathrm{~km}$ per year. This value was used to calculate the percentage of sites occupied by at least 1 egg mass within that radius. A generalized linear model was used to evaluate the statistical significance of the relationship between percentage of occupied sites and presence of damage. According to what we know from literature a monitoring site was considered damaged when defoliation level of foliage was greater than $50 \%$. We then used the historical series of data to calculate the probability that a defoliation event would occur according to the estimated model. The logit model confirmed the validity of the predictor with respect to the presence of damage, with a general accuracy greater than $90 \%$. The results suggest a revision of the sampling protocol used thus far, which requires a particularly costly and prolonged sampling effort. The method described herein should allow easier identification of forest areas exposed to damage and timelier planning of control interventions.

KEY WoRDS: gypsy moth, pest monitoring program, cork oak, generalized linear model, logistic regression

\section{INTRODUCTION}

Oaks are the most common tree species in the woods of Sardinia (Italy) and are represented mainly by the cork oak (Quercus suber L.), the downy oak (Quercus pubescens Willd) and the holm oak (Quercus ilex L.). Oak woods cover approximately 140,000 ha, more than $20 \%$ of the island of Sardinia in both mixed and pure stands, and have particular socioeconomic importance. They are periodically debarked for the commercial exploitation of the cork and in large part managed as pastures or treed cultivated fields (BullitTA et al., 2011; CAMPus et al., 2013). This intensive use leads to the precarious health of the stands, which are exposed to a series of adverse biotic and abiotic factors, the combination of which increasingly causes the phenomenon called "oak decline" (FrANCESCHINI et al., 1999; LUCIANO and FRANCESCHINI, 2013).

Leaf-eating lepidopterans are among the most important adverse biotic factors for cork oak woods. The defoliation can cause very severe physiological imbalances, especially when the outbreaks occur in dry years. In particular, the species determining the greatest damage is the gypsy moth Lymantria dispar (L.) (Lepidoptera Erebidae) (PROTA and LuCIANO, 1989; LuCIANO and ProtA, 1995), being able to completely defoliate over 60,000 ha of cork oak in a single year during its periodical abundance peaks (LUCIANO and PROTA, 1985). In the geographical areas of gypsy moth distribution, abundance of egg masses has been surveyed to predict its outbreaks. The egg masses are considered the optimal stage for the monitoring of L. dispar populations in Europe, North Africa and the USA because of their apparent straw colour, their long duration in the wild (throughout autumn and winter), and the relationship between their abundance and the subsequent degree of defoliation (LIEBHOLD et al., 1995). In the USA the population abundance has generally been estimated by direct counting of all the egg masses present on trees and shrubs of small sample plots and the results have been expressed in absolute terms as the number per hectare (CAMPBELL, 1967, 1973, 1981). There have also been sampling methods based on a combination of fixed- and variable-radius plots, in the latter case using a prism for identification of the plants on which to count the egg masses (WILSON and FONTAINE, 1978). Another technique commonly known as the "five minute walk", involves the observation and counting of egg masses while walking in the woods; after five minutes the recorded number is transformed into an absolute density by means of a previously estimated regression equation (WILSON et al., 1981). Comparative studies have shown that the method of a fixed-radius plot of 0.01 ha is more accurate than the others for the estimation over a wide range of species abundance (KolodNY-Hirsch, 1986). Egg mass density expressed in absolute terms has been used in several studies conducted in the former Yugoslavia (MAKSIMOVIC, 1953; MAKSIMOVIC et al., 1970), in Italy (LuCIANO and Prota, 1981) and in Morocco (Fraval et al., 1978).

In Sardinia, since the winter 1979-80 a monitoring network covering most of oak woods has been established, 
based on the sampling method proposed by FrAVAL et al. (1978). The network initially involved the main cork oak areas and consisted of 111 monitoring sites. In 1983 it was expanded to 166 sites, while in 1984 it was increased to 282 sites that also covered the principal holm oak woods (LuCIANO and Prota, 1982, 1985; Prota and LuCIANO, 1989). The sites were established at the sides of main roads and generally spaced $3-5 \mathrm{~km}$ apart. This network provides yearly information on the abundance of $L$. dispar. It has proved useful to make empirical predictions about the risk of defoliation in the various Sardinian forests, allowing the timely identification of the first outbreak foci characteristic of gypsy moth's progradation phase. Analysing the data available, it has been possible to demonstrate a positive correlation within a given site between the number of plants occupied by egg masses and the total number of egg masses present on 40 trees (LUCIANo et al., 2002). This result permitted reasoning about a new perspective allowing simplification of the monitoring method and a reduction of the sampling effort. In addition, the georeferencing of monitoring sites made it possible to apply spatial interpolation techniques (i.e. kriging) and to associate the main sampling variable (egg mass abundance) with other covariates, such as the frequency of outbreaks, the diffusion of the oak stands, and the geo-pedological or climatic conditions of the area surrounding each site (i.e. cokriging). This allowed to identify outbreak foci, the spread of the infestation and the location of areas most frequently attacked by the insect (CocCo et al., 2010). Finally, the monitoring network has proved indispensable in the planning of microbiological control interventions for the containment of $L$. dispar populations in the advanced progradation phase (LuCIANo et al., 2003). The microbiological control program against $L$. dispar populations has been carried out annually over ten years by using Bacillus thuringiensis serovar kurstaki (Btk) formulations (LUCIANO and LENTINI, 2012). In particular, aerial treatments have been made on the areas with the highest number of egg masses observed in the previous winter. Nevertheless, the identification of areas subjected to phytosanitary treatments have been defined empirically considering the experience gained over the years by the operators. Unfortunately, defoliations in late spring have been pointed out also in areas where egg masses have not been observed in the previous winter.

To overcome both the burden of counting egg masses and the limitations inherent in empirical predictions of the extent and intensity of defoliation, we developed a quantitative approach to estimate the degree of infestation and to support the planning of control interventions. The approach is based on: i) data on the variation in the number of sites occupied by egg masses within a forest area with homogenous vegetation cover during the progradation phase; ii) the relationship between the occupancy of sites and the presence of defoliation; iii) a methodology allowing to identify the areas with a high probability of damage based only on the site occupancy data, thus independently of the egg mass abundance.

\section{MATERIALS AND METHODS}

\section{STUDY AREA AND DATA COLLECTION}

In a previous study (CoCCO et al., 2010) all the oak woods of Sardinia were partitioned into 12 forest districts based on the predominant oak species, the degree and continuity of forest cover, the slope and elevation of the territory, and the land use. For the present study we used data from a forest district located in the north-eastern part of Sardinia (upper Gallura, north of Mount Limbara), covering ca. $640 \mathrm{~km}^{2}$ and including 38 monitoring sites. The forest cover is mainly cork oak and the soils are granitic. At each site, gypsy moth egg masses were counted each autumn-winter on 10 successive trees aligned in the main cardinal direction starting from a common central reference point (FRAVAL $e t$ al., 1978). At the same sites, the degree of damage was evaluated visually at the end of spring; the damage was expressed as percentage of defoliation according to the transparency of the crown (ConNOLA et al., 1966). To support reliability of data, the egg mass abundance and the degree of defoliation were always evaluated by the same two observers. Since 1991, large-scale experimentation on the efficacy of treatment with Btk for the control of the L. dispar population has been conducted in this area altering the relationship between the ordinary dynamics of gypsy moth populations and the corresponding degree of defoliation (LUCIANO et al., 2003). This meant that the present study was limited to the years 1984-1991 when defoliation was directly dependent on the population density within each year.

\section{DATA ANALYSIS}

Progression of egg mass occupancy of the monitoring sites

In the study area, the conclusion of the latency phase and the transition to the progradation and culmination phases of the $L$. dispar population occurred between 1984 and 1991 . The data collected during those eight years were examined to determine the progression of the percentage of sites occupied by egg masses. In particular, a site was considered occupied if it contained at least one gypsy moth egg mass. The temporal variation of the percentage of occupied sites followed a trend of logistic growth (Fig. I) and was interpolated with the equation (PRICE, 1997):

$$
y(t)=\frac{K}{\left(1+a \cdot e^{-b t}\right)}
$$

where $y$ represents the percentage of occupied sites, $t$ the time in years, $K=1$ is a parameter expressing the carrying capacity of the system which in this case corresponds to full occupancy of the available sites, $a$ and $b$ are the parameters to be estimated. Linearization of the logistic function (1), determined algebraically, gives the equation:

$$
\log \left(\frac{\mathrm{K}}{\mathrm{y}}-1\right)=\log a-b t
$$

which allows estimation of the parameters $a$ and $b$ of the regression line obtained on the semi-logarithmic plot with time $t$ on the abscissa and $\log (K / y-1)$ on the ordinate. The estimation of the parameters in the (1) was carried out by the least-squares method.

\section{Annual expansion of the area occupied by L. dispar}

The increasing percentage of sampling sites occupied by an insect species in a continuous forest district during the progradation phase translates over time into a progressive increase of the surface area occupied by the insect. This relationship allows estimation of the annual increase of the occupied area by means of various calculation methods (VAN Den Bosch et al., 1990; LeNsincK, 1997; Hill et al., 2001). This information is particularly important for the study of the spatio-temporal dynamics of animal populations and for the planning of control strategies (Hassall and Thompson, 2010; Preuss et al., 2014). In the 


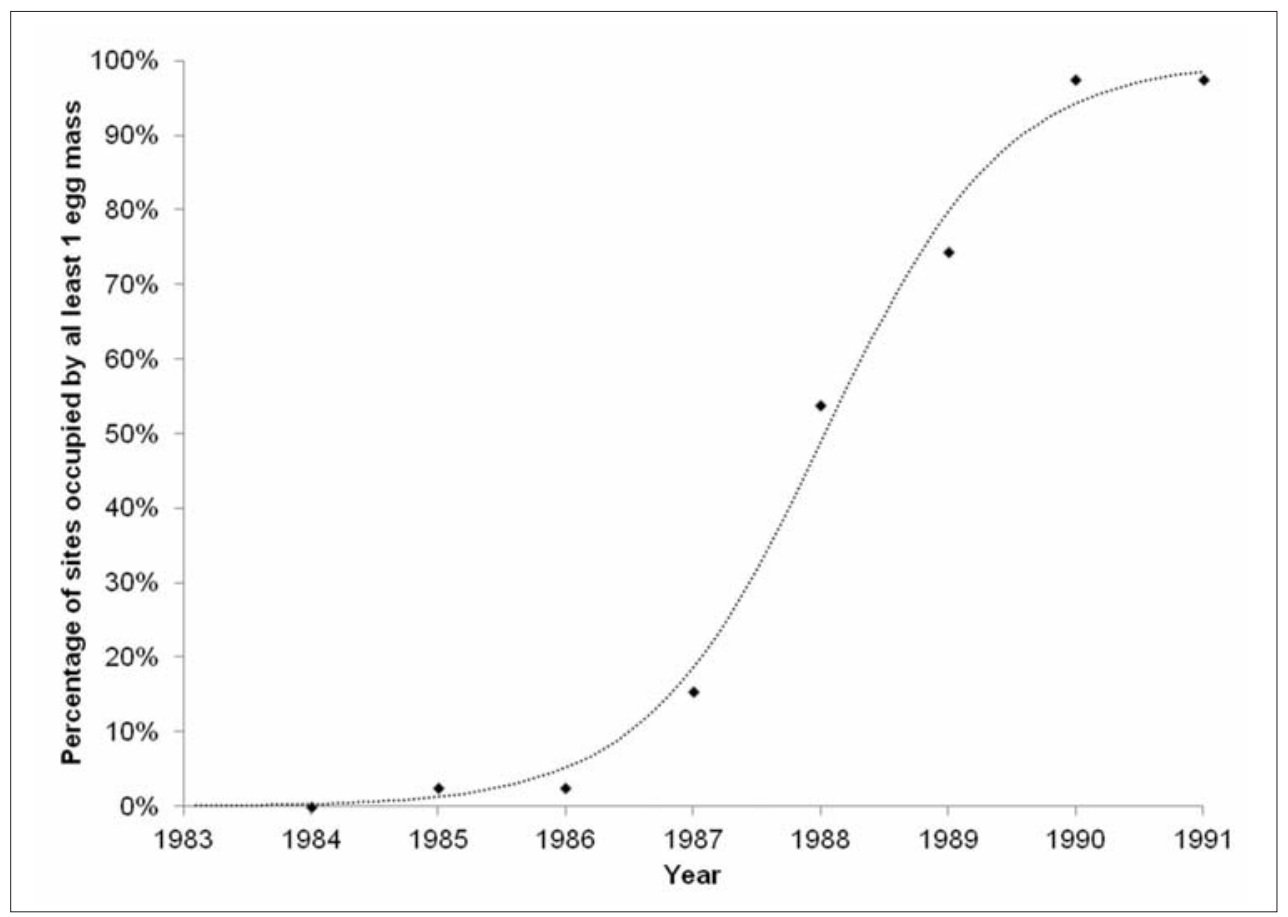

Fig. I - Logistic growth of the number of sites occupied by L. dispar egg masses in the forest district of upper Gallura during the period 1984-1991 (dots = observations, dotted line = interpolating logistic function).

present study we used the methodology proposed by HiLL et al. (2001) based on the calculation of areas (VAN DEN Bosch et al., 1990) and originally proposed to estimate the rate of expansion of Pararge aegeria (L.) (Lepidoptera Satyrinae) according to habitat availability.

Firstly, the estimation of the area annually occupied by $L$. dispar was carried out through a geographical information system (GIS). Monitoring data were included using ArcGIS software (ESRI, 2011) and the forest surface area affected by the presence of the defoliator was estimated by interpolating the occupancy data by means of the Inverse Distance Weighted (IDW) method. Secondly, square root of estimated areas occupied by insect $(x)$ was plotted against year. The radius of annual expansion was then estimated as the slope $(a)$ of the regression line $(y=a x+b)$ obtained by projecting the area occupied by the insect each year (square root of the occupied surface area) by time (LENSINCK, 1997; HiLl et al., 2001).

\section{Model of the probability of damage}

To calculate the damage probability we considered the occupancy of sites surrounding the single monitoring site as the primary variable, as a surrogate of population abundance (Mackenzie and Nichols, 2004). For each monitoring site and year we determined the percentage of surrounding sites occupied by egg masses within the calculated radius of annual expansion, including presence or absence of egg masses at the focus site. To this variable we associated the intensity of defoliation of the stand, evaluated as a binary variable with a value of 0 in cases in which the threshold of $50 \%$ crown reduction was not exceeded, corresponding to the level within which the production of cork does not decrease significantly (CAMBINI, 1971), and a value of 1 when that threshold was exceeded.

The variables defined in this way were analyzed with a generalized linear model (GLM). GLMs are widely used in biology for variables with a dichotomous response
(Mccullagh and Nelder, 1989; Wulder et al., 2006; BOLKER et al., 2008; HoSMER et al., 2013). They are also used in forestry research for estimation of the growth and mortality of trees (MONSERUD, 1976; VANCLAY, 1995; MonSERUd and SterbA, 1999; SHEN et al., 2000), as well as for the prediction and mapping of insect-induced defoliation (LAMBERT et al., 1995; MAGNUSSEN et al., 2004; FRASER and LATIFOVIC, 2005). The nature of the considered variables allowed us to use a logistic regression model to explore the relationship between the dichotomous dependent variable (the expression of the presence or absence of severe defoliation) and one or more regressors thought to influence the dependent variable (HoSMER et al., 2013).

The logistic regression model considers the percentage of site occupancy as an independent variable and the intensity of defoliation as a dichotomous dependent variable, analyzed in the form of a logit variable. The analysis was carried out through evaluation, on a logarithmic basis, of the relationship between the probability that the defoliation was greater than $50 \%(p)$ and the probability that this damage level was not exceeded ( $q=1-p)$ (BERGERUD, 1996). Generalizing, in the presence of $k$ independent variables $\left(x_{1}, \ldots, x_{k}\right)$, the logistic regression model is represented as (NORUŠIS, 2005):

$$
\log \left(\frac{p}{q}\right)=\alpha_{0}+\alpha_{1} x_{1}+\cdots \alpha_{k} x_{k}
$$

where $p$ is the probability of the event occurring (presence of damage greater than $50 \%), q$ is the probability that this event does not occur $(p+q=1), \alpha_{0}$ and $\alpha_{1}$ are constants. The model (3) can also be expressed as in (4):

$$
p=\frac{1}{1+e^{-\left(\alpha_{0}+\alpha_{1} x_{1}+\cdots \alpha_{k} x_{k}\right)}}
$$

allowing the calculation of the probability with which the dependent variable assumes a value of 1 for different values of $x$. 
The damage probabilities were calculated with $\mathrm{R}$ software (R Development CoRE TEAm, 2012) and values above a threshold of 0.5 were assigned the value of 1 (presence of damage) and all others the value of 0 (no damage) (WULDER et al., 2006).

Model validation was performed as internal validation (HARRELl et al., 1996) on the basis of the fitted statistics and the prediction error. Hence we obtained a new series of data for which we determined the Wald statistics to test the significance of the estimates of the model with respect to the real damage (HARRELL, 2001). We also calculated Nagelkerke's coefficient of determination $\left(\mathrm{R}^{2}\right)$ (NAGELKERKE, 1991) and performed Hosmer and Lemeshow's Goodness of Fit Test (Hosmer et al., 2013) for the logistic regression. The former summarizes the proportion of variance of the dependent variable (damage) that is associated with the predictors (percentage of infestation), while the latter tests the null hypothesis on the probability distributions of the fitted model. To confirm that the estimates of the model approximate the data at the $95 \%$ confidence level, the p-value of Hosmer and Lemeshow's Goodness of Fit Test must be greater than 0.05 .

The values determined in this way were compared with the observed values by means of a contingency table, on which was calculated the accuracy of the prediction for the two classes of damage $(1,0)$ expressed by the percentage of cases correctly assigned to each of them. Producer's accuracy and omission error were calculated as the true and false negative rate (i.e. specificity) of model outcomes at each category (not-damaged and damaged sites), respectively. User's accuracy and commission error were also computed as the true and false positive rate (i.e. sensitivity) of model outcomes at each category, respectively. Further, we calculated the general accuracy of the prediction as a percentage of the sum of true positives and true negatives with respect to the total observations and we calculated the confidence intervals according to the method proposed by AGRESTI and COULL (1998). In order to evaluate the goodness of the proposed method we calculated as described above general accuracy and prediction accuracy for the two classes of damage considering the presence of at least $1 \mathrm{egg}$ masses in the focal sites a predictor of damage. Consequently, accuracy values obtained by the two ways were compared.

Finally we obtained graphical representations of the annual distribution of the probability of damage in the territory (CRESSIE, 2003; ZOCCA et al., 2008) by entering the data calculated by the model in a geographical infor- mation system and interpolating them using Indicator Kriging (IK). The cut-off value of 0.5 was chosen and for each year the best semi-variogram model was selected by interpreting model outputs. Anisotropy was not considered in semi-variograms calculation. Spatial interpolation was performed only for 1988 and 1989 , as they represents observation years in which variability in damage level among sites was observed within each year (Table 1). For geostatistical analysis, data were analyzed using ArcGIS software (ESRI, 2011).

\section{RESULTS}

The analysis of the percentage of sites occupied by gypsy moth egg masses in the period 1984-1991 in Gallura showed that the value increased over time during the progradation phase according to a model of logistic growth (Fig. I).

Following this result, we used the same dataset to calculate the annual rate of expansion of the insect based on the relationship of the square root of the surface area occupied by egg masses and time. The resulting linear regression is expressed by the equation (5):

$$
y=-2044.1+5729.2 x
$$

which showed a highly significant correlation coefficient $\left(r^{2}=0.949\right)$, as confirmed by ANOVA $\left(\mathrm{F}_{1,4}=74.72\right.$; $P<0.001)$, and had an angular coefficient of 5729.2, which represents the radius (in metres) of annual expansion of the species during the progradation phase.

The value of the radius of expansion was used to calculate the percentage of sites occupied by egg masses around each sampling site. These percentages were used in the logistic regression model, from which it follows that the expected damage at a site can be estimated by evaluating only the percentage of surrounding sites occupied by egg masses, as confirmed by the Wald statistics applied to the estimates of the model (Table 2). This also highlights the possibility that the variable "percentage of surrounding sites occupied by egg masses" can be employed as a predictive tool. The values of Nagelkerke's coefficient of determination and Hosmer and Lemeshow's Goodness of Fit Test also confirm that the model provides robust estimates of the data within a confidence interval of $95 \%$ (Table 3 ).

The general accuracy of the model, calculated as the

Table 1 - Summary information about defoliation level, egg masses, site occupied by at least 1 egg mass (number and percentage of total) and damaged site (number and percentage of total) observed during 1984-1990 period.

\begin{tabular}{ccccccc}
\hline \hline Year & Defoliation (\%) & Counted egg masses & \multicolumn{2}{c}{ Site occupied by egg masses } & \multicolumn{2}{c}{ Damaged sites } \\
& Mean \pm SD & Mean \pm SD & Number & \% of total & Number $\%$ of total \\
\hline $\mathbf{1 9 8 4}$ & $0.00 \pm 0.00$ & $0.00 \pm 0.00$ & 0 & 0.00 & 0 & 0.00 \\
$\mathbf{1 9 8 5}$ & $0.00 \pm 0.00$ & $0.08 \pm 0.48$ & 1 & 2.63 & 0 & 0.00 \\
$\mathbf{1 9 8 6}$ & $0.00 \pm 0.00$ & $0.08 \pm 0.48$ & 1 & 2.63 & 0 & 0.00 \\
$\mathbf{1 9 8 7}$ & $0.00 \pm 0.00$ & $0.49 \pm 1.17$ & 6 & 15.79 & 0 & 0.00 \\
$\mathbf{1 9 8 8}$ & $36.55 \pm 33.89$ & $13.28 \pm 36.43$ & 21 & 55.26 & 20 & 52.63 \\
$\mathbf{1 9 8 9}$ & $60.53 \pm 28.06$ & $498.59 \pm 585.06$ & 29 & 76.32 & 26 & 68.42 \\
$\mathbf{1 9 9 0}$ & $96.05 \pm 13.66$ & $1192.56 \pm 482.92$ & 38 & 100.00 & 38 & 100.00 \\
\hline
\end{tabular}


Table 2 - Parameters and statistics of the logistic regression model in which the occupation of surrounding sites is considered an index of prediction of the damage caused by L. dispar.

\begin{tabular}{|c|c|c|c|c|c|c|}
\hline \multicolumn{2}{|l|}{ Model parameters } & \multicolumn{2}{|c|}{ Wald test } & \multirow{2}{*}{$\frac{\text { Nagelkerke's } R^{2}}{R^{2}}$} & \multicolumn{2}{|c|}{ Hosmer and Lemeshow's Goodness of Fit } \\
\hline Parameters & $\alpha_{i}$ & Wald & Sig. & & Chi square & Sig. \\
\hline Intercept & -5.24 & 42.9 & $<0.0001$ & 0.85 & 6.74 & 0.57 \\
\hline General occupancy & 0.09 & 56.1 & $<0.0001$ & & & \\
\hline
\end{tabular}

Table 3 - Prediction accuracy calculated on the logit model approach.

\begin{tabular}{|c|c|c|c|c|c|c|c|}
\hline & & \multicolumn{3}{|c|}{ Logit model } & \multirow[t]{2}{*}{ Producer's accuracy } & \multirow[t]{2}{*}{ Omission error } & \\
\hline & & Non-damaged & Damaged & Total & & & \\
\hline \multirow[t]{3}{*}{ Reference data } & Non-damaged & 125 & 10 & 135 & $92.59 \%$ & $7.41 \%$ & \\
\hline & Damaged & 6 & 87 & 93 & $93.55 \%$ & $6.45 \%$ & \\
\hline & Total & 131 & 97 & 228 & Overall accuracy & & \\
\hline User's accuracy & & $95.42 \%$ & $89.69 \%$ & & Lower CI & Value & Upper CI \\
\hline Commission error & & $4.58 \%$ & $10.31 \%$ & & $88.83 \%$ & $92.98 \%$ & $95.71 \%$ \\
\hline
\end{tabular}

Confidence intervals calculated at $95 \%$ confidence coefficient.

ratio of the sum of true positives and true negatives to the total number of observations, was $92.98 \%$, with lower and upper confidence intervals of $88.83 \%$ and $95.71 \%$, respectively. The accuracy of the method was high and the percentage of actually damaged sites correctly classified by the model was $93.55 \%$. General accuracy calculated by using the presence at least 1 egg mass in the focal sites as a predictor of damage was high $(88.16 \%)$, but lower than value calculated from model results (Table 4). In particular, both the percentage of correctly damaged sites and non-damaged sites showed a lower values than those of the previous approach $(84.38 \%$ and $90.91 \%$, respectively).

Semi-variograms parameters, as well as cross-validation analysis, are reported in Table 5. Among the fitted model, the best models selected for 1988 and 1989 were "Spherical" and "Exponential", respectively (Table 5). Finally, maps yielded by IK depicting the spatial variation of the damage probability (Fig. II) proved a good predictability, as the results of cross-validation showed significant correlation between predicted and expected values (Table 5).

Table 4 - Prediction accuracy calculated on the presence of at least 1 egg masses.

\begin{tabular}{|c|c|c|c|c|c|c|c|}
\hline & & \multicolumn{3}{|c|}{ Damage observed } & \multirow[t]{2}{*}{ Producer's accuracy } & \multirow[t]{2}{*}{ Omission error } & \\
\hline & & Non-damaged & Damaged & Total & & & \\
\hline \multirow[t]{3}{*}{ Egg masses } & Absence & 120 & 12 & 132 & $90.91 \%$ & $9.09 \%$ & \\
\hline & Presence & 15 & 81 & 96 & $84.38 \%$ & $18.52 \%$ & \\
\hline & Total & 135 & 93 & 228 & Overall accuracy & & \\
\hline User's accuracy & & $88.89 \%$ & $87.10 \%$ & & Lower CI & Value & Upper CI \\
\hline Commission error & & $11.11 \%$ & $12.90 \%$ & & $83.27 \%$ & $88.16 \%$ & $91.78 \%$ \\
\hline
\end{tabular}

Confidence intervals calculated at $95 \%$ confidence coefficient.

Table 5 - Parameter estimates for selected models used to describe semi-variograms of probabilities of damage in 1988 and 1989 and results of cross validation of Indicator Kriging (IK).

\begin{tabular}{|c|c|c|c|c|c|c|c|}
\hline \multirow{2}{*}{ Year } & \multicolumn{4}{|c|}{ Semi-variogram parameters } & \multicolumn{3}{|c|}{ Cross validation } \\
\hline & Model & Range (m) & Partial sill & Nugget & Mean predicted error & $* \mathbf{R}$ & $* \mathbf{p}$ \\
\hline 1988 & Spherical & 11448 & 0.2531 & 0 & 0.02 & 0.69 & $<0.01$ \\
\hline 1989 & Exponential & 20190 & 0.1453 & 0 & 0.02 & 0.43 & $<0.01$ \\
\hline
\end{tabular}

* Results of linear correlation between predicted vs. expected values 


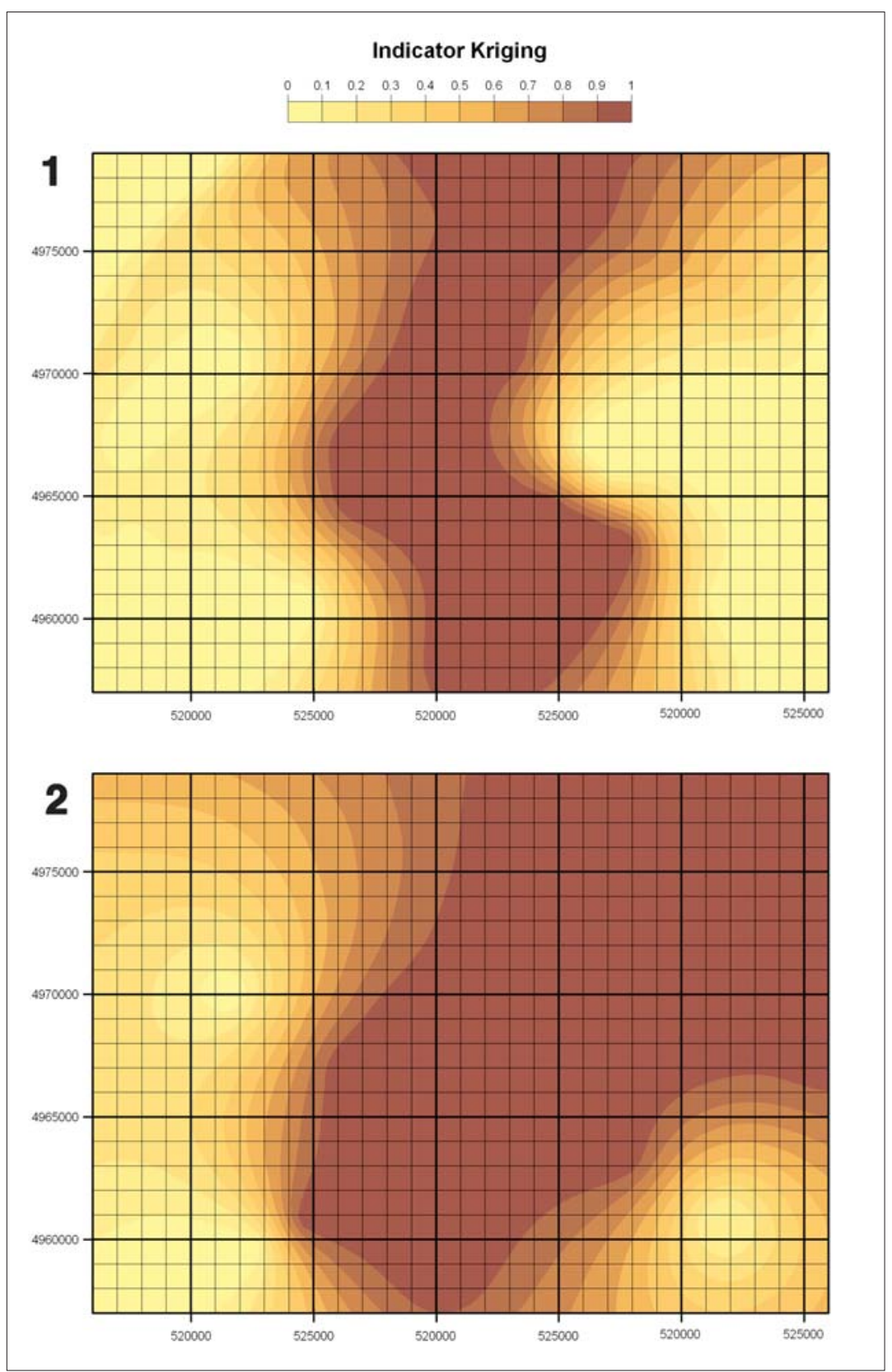

Fig. II - Maps of probability of damage for 1988 (1), and 1989 (2). Maps were made interpolating the probability values predicted by the adapted model using Indicator Kriging (IK). The $\mathrm{x}$ - and $\mathrm{y}$-axes indicate East and North coordinates (UTM Zone $32 \mathrm{~N}$, WGS84 datum) in metres, respectively.

\section{DISCUSSION AND CONCLUSIONS}

L. dispar is the most harmful pest in Sardinian cork oak stands, causing severe defoliation during the progradation phase and the population abundance peak (LUCIANO and Prota, 1985, LuCiANo et al., 1999). The progradation period is the most suitable window of time for the application of control interventions aimed at decreasing the abundance of the gypsy moth population and thus the potential damage to vegetation and forestry production. For this purpose early pest detection is necessary to identify the increasing of the territory occupied by gipsy moth egg masses representing the starting point of progradation phase. In Sardinia the monitoring of egg masses in winter has allowed identification of the sites with the highest population density (LUCIANO et al., 2002; CocCO and LUCIANO, 2012) and the areas to be subjected to microbiological control interventions have been defined empirically. Nevertheless, partial and total defoliation have often been recorded in places where egg masses were not found during the previous winter; this was very likely caused by active and passive diffusion of the species at the larval stage, as hypothesized for other lepidopterans (GILBERT et al., 2004). Although population abundance is the main sampling variable used in the monitoring of animal species (MACKENZIE and NiCHOLS, 2004), in the present study we attempted to simplify the sampling method for $L$. dispar populations by studying the relationship between the percentage of sites occupied by egg masses and the expected damage to the vegetation, as well as the radius of expansion of the species during the progradation phase. The aim was to determine whether the variable "sites occupied by egg masses" can be applied in monitoring programs and can be used to predict the damage. To this end we assumed that the probability of damage at each site would increase with the increase in the percentage of sites occupied by egg masses within a predetermined radius from the considered site. This distance, calculated as the radius of annual 
expansion, was approximately $6 \mathrm{~km}$ and allowed us to evaluate the area potentially affected by the presence of $L$. dispar. The distance estimated in this way can only be used when there is a constant expansion of the $L$. dispar population, a condition found to occur in northern Gallura during the phase of population growth, as demonstrated by the analysis of the increase in the percentage of sites occupied by egg masses over time. The results demonstrate that in the cork oak stands of Gallura the spatio-temporal dynamic of the gypsy moth population during the progradation phase follows a pattern similar to that of invasive alien species during their spread (ANDOw et al., 1990).

The estimates of the logistic regression between the damage recorded at a site and the percentage of occupancy by egg masses of the surrounding sites (within a $6 \mathrm{~km}$ radius) were highly significant. Therefore the variable "percentage of occupied sites" can be considered to be directly related to both population abundance, as demonstrated for many other animal species in which the area occupied increases with the population abundance (GASTON et al., 2000; SILESHI, 2007), and expected damage.

The $L$. dispar monitoring program in Sardinia, based on the counting of egg masses in winter, has allowed the identification of outbreak foci in each monitoring area (Cocco et al., 2010) and a partial explanation of the metapopulation dynamics of the gypsy moth in Sardinia (Gilioli et al., 2012; Bodini et al., 2014). However, counting egg masses represents a very expensive sampling method, while the mere detection of sites occupied by egg masses could facilitate monitoring operations, especially in forest environments where it is difficult to move due to the steep slopes and the structure of the trees and shrubs populations. The mere detection of the presence of egg masses would also allow a substantial increase, for a given sampling effort, of the number of monitoring sites making possible the acquisition of a larger amount of data within the same area. Moreover, it is important to underline that the use of egg masses density to predict defoliation, then the potential damage on trees, suffers from difficulty on interpretation (LIEBHOLD et al., 1993), particularly when estimated egg masses per hectare ranges from 250 to 2500 (WILliam et al., 1991).

The estimates of the fitted model were also tested to assess its predictive ability by comparing the accuracy values obtained considering the presence of at least 1 egg mass at focal sites as a predictor. The probabilities of damage calculated by using logit model coefficients had a higher accuracy $(92.59 \%)$ than those computed by the mere presence of egg masses at focal sites. Dispersal of first instar larvae by the wind is still considered the primary vehicle of spread (LEONARD, 1971; LIEBHOLD and MCMANUS, 1991; Diss et al., 1996), making possible moving even in areas where there was no egg masses and thus justifying the possibility of defoliation where egg masses were not detected in previous winter. The reliability of the result suggested the use of a geographical information system which allowed the construction of risk maps for each of the study years (Fig. II). Adoption of this methodology would allow annual precise delimitation of the areas with the highest probability of damage and would be very beneficial in the planning and management of control interventions. This would help to overcome the uncertainty inherent in the empirical evaluations performed thus far concerning the location and extension of the areas potentially exposed to the risk of defoliation.

Finally, to arrive at a general application of the model, its validity must also be studied in forest environments in which the vegetation follows a patchy distribution or consists of species other than the cork oak, such as holm oak and downy oak. This is necessary to assess the differences in fecundity and fertility of the species (LUCIANO et al., 1999) and thus indirectly affect its potential spread in the surrounding area.

\section{ACKNOWLEDGEMENTS}

This study was part of the Agreement for scientifictechnical collaboration between the Autonomous Region of Sardinia, Office of Environmental Protection, and Department of Agriculture of the University of Sassari.

Roberto Mannu gratefully acknowledges the Autonomous Region of Sardinia for financial support of his $\mathrm{PhD}$ scholarship (P.O.R. Sardegna F.S.E. Operational Programme of the Autonomous Region of Sardinia, European Social Fund 2007-2013 - Axis IV Human Resources, Objective 1.3, Line of Activity 1.3.1.).

\section{REFERENCES}

Agresti A., Coull B.A., 1998 - Approximate is better than "exact" for interval estimation of binomial proportions. Am. Stat., 52: 119-126.

Andow D.A., Kareiva P.M., LeVIN S.A., OKUBO A., 1990 Spread of invading organisms. - Landscape Ecol., 4: 177188.

BERGERUD W.A., 1996 - Introduction to logistic regression models with worked forestry examples: biometrics information handbook no.7. - Res. Br., British Columbia Ministry of Forests, Victoria, BC, USA.

Bodini A., Gilioli G., Mannu R., Luciano P., 2014 Analisi delle dinamiche di metapopolazioni di Lymantria dispar L. in Sardegna. In: Riassunti delle comunicazioni orali - XXIV Congresso Nazionale Italiano di Entomologia, Mannu R. Ed., Edizioni ISE-CNR, Sassari, Italy, pp. 170-171.

Bolker B.M., Brooks M.E., Clark C.J., Geange S.W., Poulsen, J.R., Stevens M.H.H., White J.S.S., 2008 Generalized linear mixed models: a practical guide for ecology and evolution. - Trends Ecol. Evol., 24: 127-135.

Bullitta S., Dettori S., Manchinu M., Filigheddu M.R., PILuzza G., 2011 - Characterization of Sardinian cork oak (Quercus suber L.) genetic resources for economically important traits. - Genet. Resour. Crop Ev., 58: $1007-1020$

CAMBINI A., 1971 - Valutazione dei danni causati dagli insetti defogliatori alla quercia da sughero. Atti del I Convegno Regionale del Sughero (Tempio P., 14-16 ottobre 1971), pp. 327-339.

CAMPBELL R.W., 1967 - The analysis of numerical change in gypsy moth population. - Forest Sci., Monograph 15: 133.

CAMPBELL R.W., 1973 - Forecasting gypsy moth egg-mass density. USDA Forest Service, Northeastern Forest Experiment Station, Research Paper NE-268: 1-19.

CAmpBell R.W., 1981 - Population dynamics. In: The Gypsy Moth: Research Toward Integrated Pest Management, Doane C.C. \& McManus M.L. Ed., Technical Bulletin, vol. 1584, U.S. Department of Agriculture, Forest Service,. Washington, MD, USA, pp. 65-214.

Campus S., D'angelo M., Scotti R., 2013 - Esigenze di ricerca in selvicoltura per la gestione sostenibile in Sardegna. - L'Italia Forestale e Montana, 68: 25-41. 
Cocco A., Luciano P., 2012 - Geostatistical analysis of gipsy moth outbreaks in Sardinian oak forests using a geographical information system. - IOBC/wprs Bull. 76: 155-162.

Cocco A., Cossu Q.A., Erre P., Nieddu G., Luciano P. 2010 - Spatial analysis of gipsy moth populations in Sardinia using geostatistical and climate models. - Agr. Forest Entomol., 12: 417-426.

Connola D.P., Lewis F.B., Mcdonough J.L., 1966 Experimental field techniques used to evaluate gypsy moth, Porthetria dispar, control in New York. - J. Econ. Entomol., 59: 284-287.

Cressie N., 2003 - Statistics for Spatial Data, Revised edition. John Wiley and Sons, New York, NY., 928 pp.

Diss A.L., Kunkel J.G., Montgomery M.E., LeOnard D.E., 1996 - Effects of maternal nutrition and egg provisioning on parameters of larval hatch, survival and dispersal in the gypsy moth, Lymantria dispar L. Oecologia, 106: 470-477.

ESRI, 2011 - ArcGIS Desktop: Release 10. Environmental Systems Research Institute, Redlands, CA, USA.

Franceschini A., Corda P., Maddau L., Sechi C., Ruiu P.A., 1999 - Main aspects of cork oak decline in Sardinia. - IOBC/wprs Bull., 22: 1-4.

FRASER R.H., LATIFOVIC R., 2005 - Mapping insect-induced tree defoliation and mortality using coarse spatial resolution satellite imagery. - Int. J. Remote Sens., 26: 193-200.

Fraval A., Herard F., Jarry M., 1978 - Méthodes d'échantillonnage des populations de pontes de L. dispar (Lep.: Lymantriidae) en Mamora (Maroc). - Annales de Zoologie Ecologie Animale, 10: 267-279.

Gaston K., Blackburn T.M., Greenwood J.J.D., Gregory R.D., Queen R.M., Lawton J.H., 2000 Abundance-occupancy relationships. - J. Appl. Ecol., 37: 39-59.

Gilbert M., Grégoire J.C., Freise J.F., Heitland W., 2004 - Long-distance dispersal and human population density allow the prediction of invasive patterns in the horse chestnut leafminer Cameraria ohridella. - J. Anim. Ecol., 73: 459-468.

Gilioli G., Bodini A., Cocco A., Lentini A., Luciano P., 2012 - Analysis and modelling of Lymantria dispar (L.) metapopulation dynamics in Sardinia. - IOBC/wprs Bull., 76: 163-170.

HARREll F.E., LEE K.L., MARK D.B., 1996 - Multivariable prognostic models: issues in developing models, evaluating assumptions and adequacy, and measuring and reducing errors. - Stat. Med., 15: 361-387.

HARRELL F.E., 2001 - Regression modeling strategies: with applications to linear models, logistic regression, and survival analysis. Springer-Verlag, New York, NY, USA, $\mathrm{XII}+568 \mathrm{pp}$.

Hassall C., Thompson D.J., 2010 - Accounting for recorder effort in the detection of range shifts from historical data. - Methods Ecol. Evol., 1: 343-350.

Hill J.K., Collingham Y.C., Thomas C.D., Blakeley D.S., Fox R., Moss D., Huntley B., 2001 - Impacts of landscape structure on butterfly range expansion. - Ecol. Lett., 4: 313-321.

Hosmer JR D.W., Lemeshow S., Sturdivant R.X., 2013 Applied logistic regression. John Wiley and Sons, New York, NY, USA, 528 pp.

KolODNY-HIRSCH D.M., 1986 - Evaluation of methods for sampling gypsy moth (Lepidoptera: Lymantriidae) egg mass populations and development of sequential sampling plan. - Environ. Entomol., 15: 122-127.
LAMBERT N.J., ARDÖ J., Rock B.N., VogelmanN J.E., 1995 - Spectral characterization and regression based classification of forest damage in Norway spruce stands in the Czech Republic using Landsat TM data. - Int. J. Remote Sens., 16:1261-1287.

LENSINCK R., 1997 - Range expansion of raptors in Britain and the Netherlands since 1960s: testing an individualbased diffusion model. - J. Anim. Ecol., 66: 811-826.

LEONARD D.E., 1971 - Air-borne dispersal of larvae of the gypsy moth and its influence on concepts of control. - J. Econ. Entomol., 64: 638-641.

Liebhold A.M., Mcmanus M.L., 1991 - Does larval dispersal cause the spread of gypsy moth outbreaks? North. J. Appl. For., 8: 95-98

Liebhold A.M., Elkinton J.S., Zhou G., Hohn M.E., Rossi R.E., Boettner G.H., Boettner C.W., Burnham C., Mcnamus M.L., 1995 - Regional correlation of gipsy moth (Lepidoptera: Lymantriidae) defoliation with counts of egg masses, pupae, and male moths. - Environ. Entomol., 24: 193-203.

LiebHold A.M., SimONS E.E., Sior A., UnGER J.D., 1993 Forecasting defoliation caused by the gypsy moth from field measurements. - Environ. Entomol., 22: 26-32.

Luciano P., Franceschini A., 2013 - Emergenze fitosanitarie e strategie di difesa nelle formazioni forestali della Sardegna. - L'Italia forestale e montana, 68: 123136.

Luciano P., Lentini A., 2012 - Ten years of microbiological control program against lepidopterous defoliators in Sardinian cork oak forests. - IOBC/wprs Bull., 76: 175-178.

LuCiano P., Prota R., 1981 - La dinamica di popolazione di Lymantria dispar L. in Sardegna. I. Indicatori della gradazione ricavati dalle ovideposizioni. - Studi Sassaresi III, 27: 137-160.

LuCiano P., Prota R., 1982 - Osservazioni sulla densità di popolazione di Lymantria dispar $L$ nelle principali aree subericole della Sardegna. - Studi Sassaresi III, 28: 168179.

Luciano P., Prota R., 1985 - Indagini di base per il controllo di alcuni defogliatori in ambiente forestale. In: Atti del secondo congresso nazionale della società italiana di ecologia: Moroni A., Anelli A. \& O Ravera (Ed.), Atti 5, Edizioni Zara, Parma, Italy, pp. 823-827.

Luciano P., Prota R., 1995 - Insect pests in Sardinian cork-oakforests. - IOBC/wprs Bull., 18: 1-7.

Luciano P., Lentini A., CAO O.V., 2003 - La lotta ai lepidotteri defogliatori delle sugherete in Provincia di Sassari. Industria grafica Poddighe s.r.1., Sassari, Italy, 71 pp.

Luciano P., Lentini A., Dettori C., Solinas V., Sanna PAssino G., 1999 - Gypsy moth development on foliage of several oaks in Sardinia. - IOBC/wprs Bull., 22: 89-93.

LuCiAno P., LENTINI A., GianNASi M.P., BRUNDU G., 2002 La previsione delle infestazioni nelle sugherete della Sardegna. In: Il Monitoraggio Fitosanitario delle Foreste; Guidotti A. Ed., Quaderno ARSIA 2/2002, ARSIA, Italy, pp. 67-73.

MACKenZIE D.I., Nichols J.D., 2004 - Occupancy as a surrogate for abundance estimation.- Anim. Biodivers. Conserv., 27: 461-467.

Magnussen S., Boudewyn P., Alfaro R., 2004 - Spatial prediction of the onset of spruce budworm defoliation. The Forestry Chronicle, 80: 485-494.

Maksimovic M., 1953 - Some observations about gradation crisis of gypsy moth in plane and mountain forests in 1950. - Zastita Bilja, 15: 12-27. 
Maksimovic M., BJegovi P., Vasiljevic L., 1970 Maintaining the density of gypsy moth enemies as a method of biological control. - Zastita Bilja, 21: 3-15.

Mccullagh P., Nelder J.A., 1989 - Generalized Linear Models. 2nd edn. Chapman and Hall, London, UK, XVIII $+511 \mathrm{pp}$.

MonserUd R.A., STERBA H., 1999 - Modeling individual tree mortality for Austrian forest species. - Forest Ecol. Manag., 113: 109-123.

MONSERUD R.A., 1976 - Simulation of forest mortality. Forest Sci., 22: 438-444.

NAGELKERKE N.J.D., 1991 - A note on a general definition of the coefficient of determination. - Biometrika, 78: 691692.

NorUŠIS M.J., 2005 - SPSS 13.0 Advanced Statistical Procedures Companion. Prentice Hall, New Jersey, NY, USA, 614 pp.

Preuss S., Low M., Lundhagen A.C., Berggren Å., 2014 - Evaluating range-expansion models for calculating nonnative species' expansion rate. - Ecol. Evol., 4: 28122822.

PrICE P.W., 1997 - Insect Ecology. John Wiley and Sons, New York, NY, USA, 888 pp.

Prota R., Luciano P., 1989 - Elementi di previsione delle infestazioni in sugherete sarde e prospettive di difesa. In: Atti Convegno sulle avversità del bosco e delle piante arboree da legno; Accademia Italiana Di Scienze Forestali And Accademia Nazionale Italiana Di Entomologia (Ed.), Giorgi e Gambi, Firenze, Italy, pp. 287-304.

R Core TEAm, 2012 - R: A Language and Environment for Statistical Computing. R Foundation for Statistical Computing, Vienna, Austria.

Shen G., Moore J.A., Hatch C.R., 2000 - The effect of nitrogen fertilization, rock type, and habitat type on individual tree mortality. - Forest Sci., 47: 203-213.
Sileshi G., 2007 - A method for estimating insect abundance and patch occupancy with potential applications in large-scale monitoring programmes. - Afr. Entomol., 15: 89-101.

Van Den Bosch F., Metz J.A.J., Diekmann O., 1990 - The velocity of spatial population expansion. - J. Math. Biol., 28: 529-565.

VANCLAY J.K., 1995 - Growth models for tropical forests: a synthesis of models and methods. - Forest Sci., 41: 7-42.

Williams D.W., Fuester R.W., Metterhouse W.W., BALAAM R.J., Bullock R.H., ChIANESEI R.J., 1991 - Oak defoliation and population density relationships for the gypsy moth (Lepidoptera: Lymantriidae). - J. Econ. Entomol., 84: 1508-1514.

WILSON R.W. JR, Fontaine G.A., 1978 - Gypsy moth handbook: gypsy moth egg mass sampling with fixed-and variable-radius plot. - USDA Agricultural Handbook 523, pp. 1-46.

WILSON R.W. JR, IVANOWSKY W.M., TALERICO R.L., 1981 Direct evaluation. In: The Gypsy Moth: Research Toward Integrated Pest Management, Doane C.C. \& Mcmanus M.L. (Ed.). Technical Bulletin, vol. 1584, U.S. Department of Agriculture, Forest Service, Washington, MD, USA, pp. 34-38.

Wulder M.A., White J.C., Bentz B., Alvarez M.F., Coops N.C., 2006 - Estimating the probability of mountain pine beetle red-attack damage. - Remote Sens. Environ., 101: 150-166.

Zocca A., Zanini C., Aimi A., Frigimelica G., LA Porta N., BATTISTI A., 2008 - Spread of plant pathogens and insect vectors at the northern range margin of cypress in Italy. Acta Oecol., 33: 307-313. 
166 - Blank Page 